\title{
MINOR REACTIONS DUE TO MODERN METAL
}

\author{
J. H. Hicks and W. H. Cater, Birmingham, England \\ From the Birmingham Accident Hospital
}

One of the most desirable properties of a metal used for surgical implants and at the same time one of the most difficult to achieve, is freedom from corrosion. A great advance was made when stainless steels were introduced thirty years ago, but further experience has shown that the various members of this group differ considerably in their resistance (Fig. 1). Even the most recent one, 18/8 Mo steel, upon which much hope has been pinned, is proving to be not entirely free from corrosion (Scales, Winter and Shirley 1959).

It is true that our standards are rising: whereas in the past a removed implant pitted all over with black corrosion cavities was a familiar sight, we now look askance at the slightest loss of surface discernible only with a magnifying glass. This is because we are gradually realising that the chemical products of corrosion cause inflammatory reactions which, with the secondary sepsis that often follows, account for many of the troubles associated with

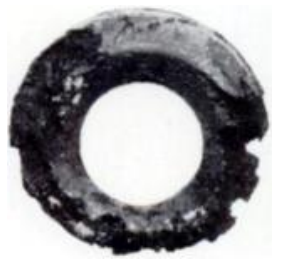

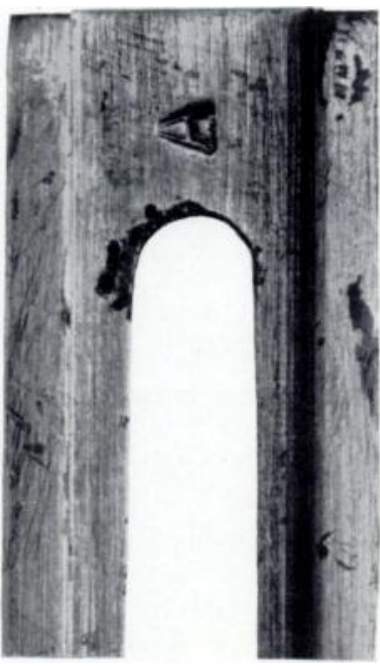

FIG. 1

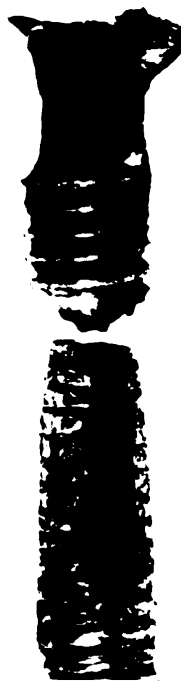

c

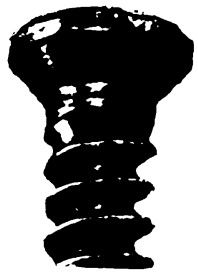

The four stainless steels that have been used in bone surgery, showing corrosion. (a) chrome steel. (b) FSL. (c) EMS. (d) 18/8 Mo.* These are depicted in historical sequence 18/8 Mo being the one in current use. Chrome steel (regularly) and EMS (rarely) corrode as badly as this even in isolation. The FSL plate $(b)$ had been in contact with an actively corroding dissimilar screw like that shown in $(c)$. The 18: Mo screw $(d)$ had been in contact with an 18/8 Mo plate. In each instance the corrosion depicted is the worst encountered with the particular steel.

metallic surgical implants. This can be true even when the defects in the metal are invisible. The incidence of inflammatory reactions is the most sensitive way of measuring the comparative value of the different metals.

A clinical survey has been made of cases in which metal was implanted between 1947 and the end of 1958. This survey extends into the period of modern metals, namely 18/8 Mo steel and cobalt-chrome alloy, and the present situation can therefore be properly assessed.

* Popular names are used throughout the text. Synonyms and precise definitions of the various steels are given in the Appendix. 
MATERIAL

The material consisted of 500 platings (tibia and forearm). The records were searched to discover how many wounds showed delay in healing or developed late inflammatory complications attributable to the presence of metal. Signs and symptoms of the severer reactions have been described previously (Hicks 1958) and those of the minor reactions are

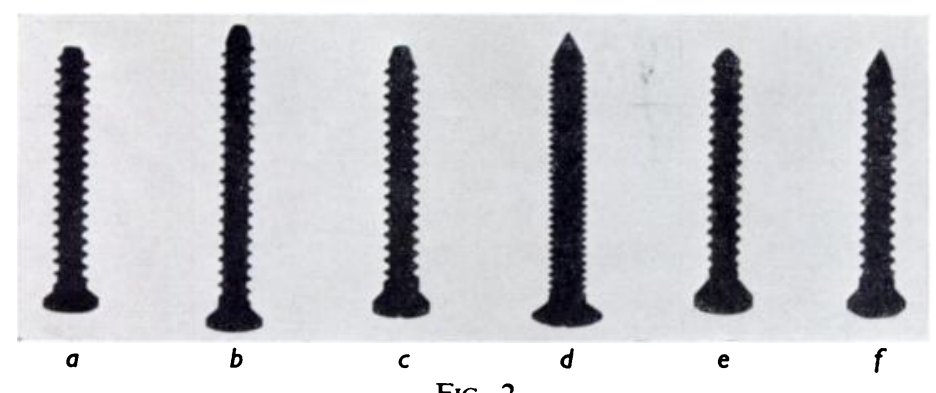

FiG. 2

Identification of various screws from radiographs. (a) Austenal's "Vitallium," old style. (b) Deloro Stellite's "Vinertia." (c) Austenal's “ Vitallium," new style. (d) Down Bros.' fine-thread; FSL if purchased before 1949 or 1950, EMS if purchased between 1950 and $1954,18 / 8$ Mo if purchased after mid-1954. (e) Zimmer's SMo. $(f)$ London Splint Co.'s 18 8 Mo steel. Plates also can be similarly identified in many cases.

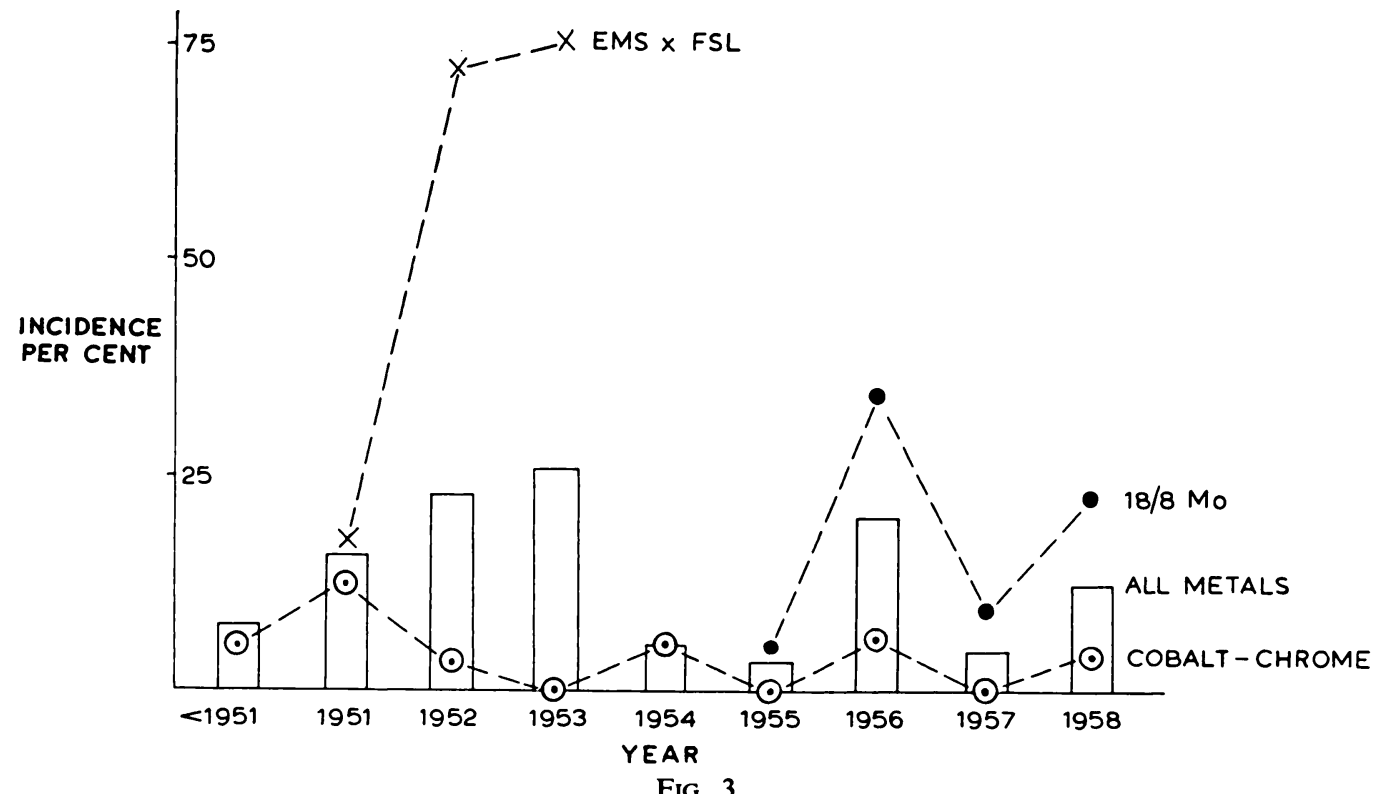

Incidence of " obligatory plate removals" with cobalt-chrome alloy $(\mathrm{Co}-\mathrm{Cr}), 18 / 8 \mathrm{Mo}$ and the EMS $\times$ FSL pair.

described below. In the latter half of the survey the records had often dealt specifically with this feature, but the diagnosis could be made with considerable certainty even when this was not so. It was decided to designate as " significant" or " unsatisfactory" any reaction severe enough to require removal of the plate. Removals for other reasons, such as skin necrosis with breakdown of the wound and exposure of metal, could nearly always be recognised and these and routine removals provided useful controls. Studies were made of the histology of many of the wounds in recent cases, and these often helped to confirm the diagnosis. The percentage of " obligatory plate removals" was worked out for each year.

VOL. 44 B, NO. 1, FEBRUARY 1962 
TABLE I

Number of Metal implants Requiring Removal Because of Corrosion

\begin{tabular}{|c|c|c|c|c|c|c|c|c|c|c|}
\hline \multirow[b]{2}{*}{ Type of metal } & \multicolumn{2}{|c|}{ Before 1951} & \multicolumn{2}{|c|}{1951} & \multicolumn{2}{|c|}{1952} & \multicolumn{2}{|c|}{1953} & \multicolumn{2}{|c|}{1954} \\
\hline & $\begin{array}{c}\text { Number } \\
\text { of } \\
\text { implants }\end{array}$ & $\begin{array}{l}\text { Number } \\
\text { of } \\
\text { removals }\end{array}$ & $\begin{array}{c}\text { Number } \\
\text { of } \\
\text { implants }\end{array}$ & $\begin{array}{c}\text { Number } \\
\text { of } \\
\text { removals }\end{array}$ & $\begin{array}{c}\text { Number } \\
\text { of } \\
\text { implants }\end{array}$ & $\begin{array}{c}\text { Number } \\
\text { of } \\
\text { removals }\end{array}$ & $\begin{array}{c}\text { Number } \\
\text { of } \\
\text { implants }\end{array}$ & $\begin{array}{c}\text { Number } \\
\text { of } \\
\text { removals }\end{array}$ & $\begin{array}{c}\text { Number } \\
\text { of } \\
\text { implants }\end{array}$ & $\begin{array}{c}\text { Number } \\
\text { of } \\
\text { removals }\end{array}$ \\
\hline $\begin{array}{l}\text { Cobalt-chrome } \\
\text { alloy (ABE, 650) }\end{array}$ & 19 & 1 & 8 & 1 & 32 & 1 & 41 & 0 & 35 & 2 \\
\hline FSL (ABE, 300) & 9 & 0 & - & - & - & - & - & - & - & - \\
\hline $\begin{array}{l}\text { ?FSL ? EMS } \\
\text { (ABE, } 220) \times \text { FSL }\end{array}$ & - & - & 17 & 3 & 14 & 10 & 21 & 16 & - & - \\
\hline $\begin{array}{l}18 / 8 \mathrm{Mo} \\
(\mathrm{ABE}, 480)\end{array}$ & 1 & 0 & - & - & - & - & - & - & - & - \\
\hline $\begin{array}{l}18 / 8 \mathrm{Mo} \\
\text { cobalt-chrome } \\
\text { alloy or FSL }\end{array}$ & 13 & 2 & - & - & 1 & 0 & - & - & - & - \\
\hline Total, all metals & 42 & 3 & 25 & 4 & 47 & 11 & 62 & 16 & 35 & 2 \\
\hline
\end{tabular}

$x$ indicates metals in contact with each other.

The numbers after the letters "ABE" are the "anodic back-EMF" values (Clarke and Hickman 1953). Results here are seen to vindicate this in vitro method of assessing corrodibility.

In addition to the cases included there were three in which washers made of chrome steel (ABE, 90) were inadvertently used. All showed gross corrosion (Fig. $1(a)$ ) and had to be removed. This steel was used commonly for Smith-Petersen nails in the 1930's.

The identity of the metal was established in each case from a study of the radiographs. For the first six years identification depended partly upon indirect evidence such as particular characteristics of the radiograph (Fig. 2), coupled with a knowledge of the source of the item from our stock-books and of the history of the availability of the different steels. In the latter half of the survey direct metallurgical tests on removed metal gave a positive identification of the items removed and provided a check on the accuracy of the larger number identified radiographically.

The least definite identification was of the FSL screws ( $d$ in Fig. 2) because of the lapse of time and because they were identical in appearance with the later EMS and 18/8 Mo screws from the same manufacturer. The differentiation is dependent upon the date of the change-over which the manufacturer said occurred in 1949 but which seems, to judge from the sudden rise in the incidence of reactions, more likely to have occurred in 1951. This discrepancy can be accounted for by the delay before the screws reached the patients. Although identification is partly dependent upon information from the manufacturers the authors are satisfied from several personal discussions that their knowledge of the materials they use is almost always accurate. What on this occasion is supposed to be FSL therefore almost certainly is.

\section{RESULTS}

Four metals came into the survey, namely cobalt-chrome alloy ("Vitallium "), 18/8 Mo, EMS, and FSL.

The number of occasions on which symptoms were severe enough to justify removal of the plate, together with the total number of platings with each type of metal, is given in Table I and in Figure 3. The steady undercurrent of minor trouble is revealed in the 4 to 20 per cent of obligatory removals over the recent four years when modern metal was in use exclusively. Of the two metals now used cobalt-chrome alloy is seen to have the lower removal rate and 
TABLE I-continued

Number of Metal implants Requiring Removal Because of Corrosion

\begin{tabular}{|c|c|c|c|c|c|c|c|c|c|c|}
\hline \multicolumn{2}{|c|}{1955} & \multicolumn{2}{|c|}{1956} & \multicolumn{2}{|c|}{1957} & \multicolumn{2}{|c|}{1958} & \multirow{2}{*}{$\begin{array}{c}\text { Total } \\
\text { number of } \\
\text { implants }\end{array}$} & \multirow{2}{*}{$\begin{array}{c}\text { Total } \\
\text { number of } \\
\text { removals }\end{array}$} & \multirow[b]{2}{*}{ Percentage } \\
\hline $\begin{array}{c}\text { Number } \\
\text { of } \\
\text { implants }\end{array}$ & $\begin{array}{c}\text { Number } \\
\text { of } \\
\text { removals }\end{array}$ & $\begin{array}{c}\text { Number } \\
\text { of } \\
\text { implants }\end{array}$ & $\begin{array}{c}\text { Number } \\
\text { of } \\
\text { removals }\end{array}$ & $\begin{array}{c}\text { Number } \\
\text { of } \\
\text { implants }\end{array}$ & $\begin{array}{c}\text { Number } \\
\text { of } \\
\text { removals }\end{array}$ & $\begin{array}{c}\text { Number } \\
\text { of } \\
\text { implants }\end{array}$ & $\begin{array}{c}\text { Number } \\
\text { of } \\
\text { removals }\end{array}$ & & & \\
\hline 41 & 0 & 31 & 2 & 53 & 0 & 47 & 2 & 307 & 9 & 3 \\
\hline- & - & - & - & - & - & - & - & 9 & 0 & \\
\hline - & - & - & - & - & - & - & - & 52 & 29 & 56 \\
\hline 13 & 1 & 32 & 11 & 34 & 3 & 35 & 8 & 115 & 23 & 20 \\
\hline 3 & 1 & 3 & 0 & 2 & 1 & - & - & 22 & 4 & 18 \\
\hline 57 & 2 & 66 & 13 & 89 & 4 & 82 & 10 & 505 & 65 & 13 \\
\hline
\end{tabular}

$x$ indicates metals in contact with each other.

The numbers after the letters "ABE" are the "anodic back-EMF" values (Clarke and Hickman 1953). Results here are seen to vindicate this in vitro method of assessing corrodibility.

In addition to the cases included there were three in which washers made of chrome steel (ABE, 90) were inadvertently used. All showed gross corrosion (Fig. $1(a)$ ) and had to be removed. This steel was used commonly for Smith-Petersen nails in the 1930's.

18,8 Mo steel the higher. The infiltration of our theatre stock by EMS a few years previously is revealed by a tremendous rise in the removals of this particular type of screw.

Observations on the clinical picture-A typical reaction with $18 / 8$ Mo is shown in Figure 4. This is much milder than the corrosion reaction as previously described (Hicks 1958) when EMS was the cause and is difficult to discern in this photograph. It was sufficient to make the patient accept the offer of plate removal, whereupon all symptoms except the scaling subsided. Sometimes there is merely a local area of warmth or of tenderness over one screw, a reaction so slight that it is only recognisable because it comes at one extreme of the whole graded series of reactions. At the other extreme is the reaction shown in Figure 5 (although this ought not to be considered representative). In the forearm a characteristic effect is an oedematous swelling, without redness, in the region of the tendons of the extensores carpi radialis and thumb abductors (Fig. 6). There is often crepitus on movement, and the condition therefore resembles the idiopathic tenosynovitis that occurs at this site. The irritation in these cases is thought to be more likely chemical than mechanical.

\section{DISCUSSION}

The most important conclusion from this survey is that $18 / 8 \mathrm{Mo}$, the steel at present exclusively on sale in this country for surgical implants and one that metallurgists can scarcely improve upon, is clinically not very satisfactory. It is estimated that approximately one in every twenty screws made of this metal became visibly corroded. The higher incidence (one in seven) found by Scales $e t$ al. is probably the result of their analysing "screws removed " instead of "screws inserted." Whatever the exact incidence, the result is that in one in five cases of plating with $18 / 8 \mathrm{Mo}$, symptoms made plate removal desirable.

Cobalt-chrome alloy on the other hand was much more satisfactory; only one in every thirty-three plates required removal. Even this may be an underestimate of its excellence,

vOL. 44 B, NO. 1, FEBRUARY 1962 
the real cause in those that gave trouble possibly being metallic transfer (see below). Visible corrosion of the metal has never been seen in cobalt-chrome alloy.

EMS, as has been previously reported, is very likely to produce a corrosion reaction (Cater and Hicks 1956).

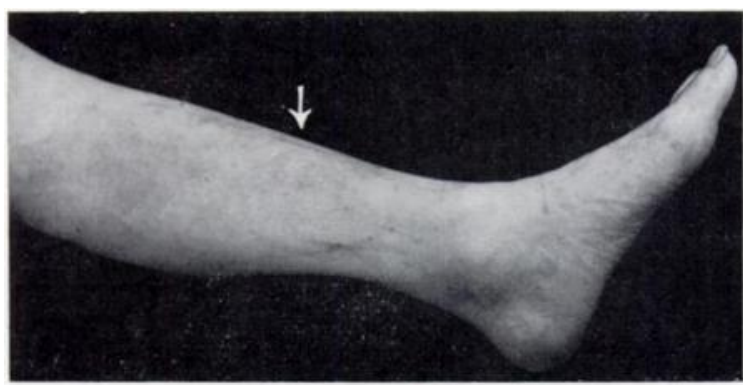

$a$

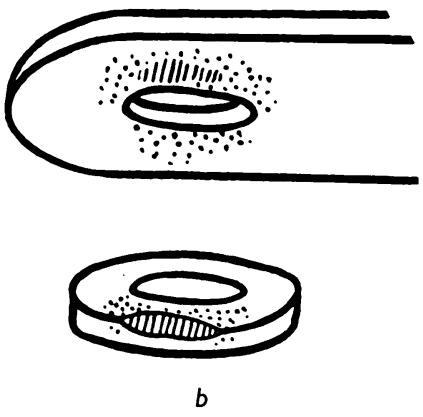

FIG. 4

(a) Typical reaction with 18'8 Mo. There was slight redness, oedema, and mild tenderness at the point indicated and the skin is showing slight scaling. Night pain developed after a month or two. (b) Sketch showing the plate and a washer after removal. (Shading indicates area of roughening and loss of surface. Stippling indicates area of brown staining.) Histology: inflammation with metal infiltration. Bacteriology: sterile.

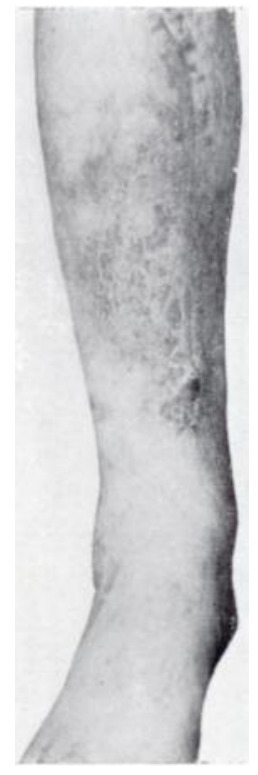

FIG. 5
Figs. 5 AND 6

Figure 5-Exceptionally severe 18/8 Mo reaction. This is more like a typical EMS reaction. A large area of eczema and a small abscess can be seen. Figure 6Typical reaction with $188 \mathrm{Mo}$ in the forearm resembling tenosynovitis. Considerable thickening can be seen around the tendons overlying the plate and there was slight tenderness at one end.

FSL was fairly satisfactory. The number of unmixed platings with FSL was small, but an additional eleven in which this metal was mixed with $18 / 8$ Mo or with cobalt-chrome alloy are known. Only two of these showed a significant reaction. In the comparatively small number of patients in whom this metal was used therefore it appears to be as reliable as the more widely accepted $18 / 8$ Mo.

The situation with $18 / 8 \mathrm{Mo}$ is not as bad as it might seem from the above figures. Not only are the reactions less severe than with most other stainless steels but also they are slower to reach significant proportions. To be forced to remove a plate before union has occurred 
is to be on the threshold of disaster, and with the EMS $\times$ FSL pair this had to be done in nearly one-third of the cases. With $18 / 8$ Mo this dangerous situation arose only twice in the twenty-three removals (that is, twice in the 115 insertions). With cobalt-chrome alloy it arose twice in the nine removals (that is, twice in the 307 insertions).

The question arises why stainless steel is used at all. The answer does not lie in the realm of surgery. The most compelling reason is ease of manufacture. Stainless steel can be rolled, drawn, stamped, pressed, threaded, forged, drilled, cut and ground, whereas the cobalt-chrome alloy in common use can be submitted to the last three of these processes to a limited extent only and to the others not at all. Until the recent introduction of "wrought Vitallium alloy" every cobalt-chrome appliance had to be laboriously cast. The preliminaries are so expensive that it is easy to understand a certain caution on the part of the manufacturer in embarking on new designs or modifying old ones until the success of the new item is assured. Stainless steel is, therefore, almost essential in the development of prototypes, but ought to be abandoned as soon as the design is firmly established. Once the success of the new item is assured there are no difficulties in getting it made in cobalt-chrome alloy.

The place of metallic transfer-The amount of inflammation with metal infiltration in the tissues around an implant has been shown by Bowden, Williamson and Laing (1955) and Laing (1958) to be increased when ordinary steel drills and screwdrivers are used for insertion of the metal. This they showed to be due to the transfer of minute quantities of the dissimilar metal from the tool. This transferred metal itself corrodes and at the same time encourages corrosion in the recipient metal. Most of the effects they described were only detectable microscopically, and it was not convincingly demonstrated that the reaction was of clinical importance (Hicks 1957). In the present series, contrary to the advice given in the above papers, all the platings have been done with the aid of ordinary steel drills and screwdrivers, the former, in fact, having been purchased from the local ironmonger. The fact that only 3 per cent of the cobalt-chrome platings have given reactions of clinical significance and that some of these were mild or doubtful examples, shows that metallic transfer cannot play a large part in causing trouble. Laing's histological findings were present very often (even in the cobalt-chrome platings) but the reaction nearly always remained clinically inappreciable. In other words, the histological test is unnecessarily sensitive for practical purposes.

The possibility remains however that the adoption of tools of a suitable composition, as recommended by Laing, might effect a reduction in the 3 per cent incidence of reactions with cobalt-chrome alloy and a more substantial reduction in the incidence with $18 / 8$ Mo steel. The prospect of curing the trouble altogether with stainless steel is remote because the constant position of the defect under the bevel of the $18 / 8$ Mo screws strongly suggests some other cause-possibly fretting or possibly crevice corrosion (Anon. 1949)—not connected with metallic transfer.

Mixed metals-18/8 Mo when mixed with cobalt-chrome alloy or with FSL gave no higher incidence of corrosion reaction than when unmixed. It appears therefore that, with the comparatively good metals, dissimilarity is not very important. With the poorly resistant stainless steels (for example, EMS), dissimilarity does matter because the incidence and severity of reactions is much increased. With the very poor stainless steels (for example, chrome-steel), dissimilarity is unimportant in a different sense because severe corrosion occurs even when they are used alone.

In vitro demonstration of corrodibility-A vivid demonstration of the corrodibility of all stainless steels and of the different degrees of corrodibility of the various members of the series, is provided by the muriatic acid tests (Miller 1945). Briefly, these consist in applying hot, moderately strong, hydrochloric acid to the metal. The result is disconcerting for anyone who is under the impression that stainless steels are inert. EMS bubbles furiously and comes out black after five minutes. FSL bubbles moderately and comes out grey. 18/8 Mo bubbles gently but does not lose its polished surface within the brief period of the test. Cobalt-chrome 
alloy bubbles very slightly after a long time and is quite unaffected in appearance (the same is true for titanium). This can be taken to represent, on a vastly accelerated scale, what occurs in the body.

\section{SUMMARY}

1. Two of the three metals at present in use in orthopaedic surgery have been studied to assess their tendency to cause wound reactions.

2. Cobalt-chrome alloy proved to be the better, the incidence of obligatory plate removal being at most 3 per cent. Visible corrosion in this metal never occurred.

3. $18 / 8$ Mo stainless steel proved to be the poorer, the incidence of obligatory plate removal being 20 per cent. Visible corrosion of the metal is estimated to have occurred in about 5 per cent of screws inserted.

4. Regardless of such accelerating factors as metallic transfer, 18/8 Mo steel may have to be accepted as inherently more susceptible to corrosion than is cobalt-chrome alloy.

5. The qualities of two other stainless steels also became evident. Previous work describing the very bad situation arising from the use of EMS was confirmed. By contrast, a steel that was in use before 1951 gave little trouble. This steel was probably FSL.

\section{REFERENCES}

Anon. (1949): Corrosion Resisting Properties of the Austenitic Chromium-Nickel Stainless Steels. New York: International Nickel Co.

Bowden, F. P., Williamson, J. B. P., and Laing, P. G. (1955): The Significance of Metallic Transfer in Orthopaedic Surgery. Journal of Bone and Joint Surgery, 37-B, 676.

CATER, W. H., and HiCKS, J. H. (1956): The Recent History of Corrosion in Metal used for Internal Fixation. Lancet, ii, 871.

Clarke, E. G. C., and Hickman, J. (1953): An Investigation into the Correlation between the Electrical Potentials of Metals and their Behaviour in Biological Fluids. Journal of Bone and Joint Surgery, 35-B, 467.

Hicks, J. H. (1957): Metallic Corrosion in Orthopaedic Surgery. Lancet, i, 1,147.

Hicks, J. H. (1958): In Modern Trends in Surgical Materials. Edited by L. Gillis. London: Butterworth \& Co. (Publishers) Ltd.

LaING, P. G. (1958): The Significance of Metallic Transfer in the Corrosion of Orthopaedic Screws. Journal of Bone and Joint Surgery, 40-A, 853.

Miller, H. W. (1945): Spot Identification of Stainless Steals. Metals and Alloys, 21, 1,364.

Scales, J. T., Winter, G. D., and Shirley, H. T. (1959): Corrosion of Orthopaedic Implants. Journal of Bone and Joint Surgery, 41-B, 810.

\section{APPENDIX}

Nomenclature of Metals

(With one exception popular names have been used in the text.

Synonyms or near equivalents are given below.)

\begin{tabular}{|c|c|c|c|c|}
\hline \multicolumn{2}{|c|}{ Classification } & \multicolumn{2}{|r|}{ Popular name } & $\begin{array}{c}\text { Synonyms or near equivalents } \\
\text { (with reference) }\end{array}$ \\
\hline \multirow{5}{*}{$\begin{array}{l}\text { Stainless } \\
\text { steels }\end{array}$} & Martensitic & & Chrome steel & En 57 (British Standard) \\
\hline & & $18 / 8\{$ & EMS & $\begin{array}{l}\text { En } 58 \mathrm{M} \text { (British Standard) } \\
18 / 8 / \mathrm{Ti} \text { (Scales } \text { et al.) } \\
303 \text { (American Bureau of Standards) }\end{array}$ \\
\hline & Austenitic & & FSL & $\begin{array}{l}\text { En 58E (British Standard) } \\
304 \text { (American Bureau of Standards) }\end{array}$ \\
\hline & & & $18 \mathrm{Mo}$ & $\begin{array}{l}\text { En 58J (British Standard) } \\
316 \text { (American Bureau of Standards) }\end{array}$ \\
\hline & & & "Vitallium " & $\begin{array}{l}\text { Cobalt-chrome alloy, } \mathrm{Co}-\mathrm{Cr} \\
\text { "Vinertia" }\end{array}$ \\
\hline $\begin{array}{l}\text { Since th } \\
\text { tungsten } \\
\text { inadequ }\end{array}$ & for identif & of “" & $\begin{array}{l}\text { "wrought "Vi } \\
\text { itallium" and } \\
\text { The data in th } \\
\text { sting alloy (co }\end{array}$ & $\begin{array}{l}\text { ium, alloy" (cobalt-chrome-nickel- } \\
\text { term " cobalt-chrome" both become } \\
\text { resent paper refer only to the original } \\
\text { t-chrome molybdenum). }\end{array}$ \\
\hline
\end{tabular}

